\title{
O impacto da orientação pré-operatória na recuperação do paciente cirúrgico
}

Recebido em: 14/03/2011

Aceito em: 26/07/2011

Jeferson dos Santos ${ }^{1}$

Luizita Henckmeier ${ }^{2}$

Silvana Alves Benedet ${ }^{3}$

Este estudo teve como objetivos caracterizar as orientações pré-operatórias realizadas pelos enfermeiros e identificar o impacto da orientação pré-operatória na recuperação do paciente cirúrgico. O estudo foi realizado numa unidade cirúrgica de hospital de ensino de Santa Catarina. A população constituiu-se de seis enfermeiros e 25 pacientes cirúrgicos. Observação sistematizada e entrevistas semiestruturadas foram utilizadas para a coleta de dados. Os resultados evidenciaram que a orientação pré-operatória individualizada proporcionou tranquilidade, bem-estar, otimismo, diminuindo o medo e a ansiedade dos pacientes que se mobilizaram precocemente e realizaram exercícios respiratórios, resultando em recuperação mais rápida e menos complicações.

Descritores: Enfermagem Cirúrgica, Educação em Saúde, Enfermagem Pré-Operatória.

\section{The impact of the preoperative guideline on surgical patient recovery}

This study aimed at characterizing the preoperative guidelines performed by nurses; to identify the impact of preoperative surgical patient. To this end, we conducted semi-structured interviews with patients from the surgical clinic of a Santa Catarina teaching hospital and nurses of the clinic. The population consisted of 06 nurses and 25 surgical patients. We concluded that the orientation of the patients did express feelings of tranquility, wellness and optimism, as well as diminish the fear and anxiety. All these, together with early mobilization were important factors that contributed to a faster recovery and lower rate of complications.

Descriptors: Surgical Nursing, Education in Health, Preoperative Nursing.

\section{El impacto de la orientación preoperatoria en la recuperación del paciente quirúrgico}

Este estudio tuvo como objetivo caracterizar la orientación preoperatoria en la recuperación de pacientes quirúrgicos; identificar el impacto de la orientación preoperatoria en el paciente quirúrgico. El estudio se realizó en una unidad quirúrgica del hospital de educación de Santa Catarina. La población consistió en 06 enfermeras y 25 pacientes quirúrgicos. Se concluye que la orientación hizo con que los pacientes manifestaran sentimientos de tranquilidad, bien estar, optimismo, disminución del miedo, la ansiedad y que se movilizaron precozmente. Esos factores contribuyeron, consecuentemente, para una recuperación más rápida y con un índice menor de complicaciones.

Descriptores: Enfermería Quirúrgica, Educación en Salud, Enfermería Preoperatoria.

\section{INTRODUÇÃO}

U $\mathrm{m}$ procedimento cirúrgico não é algo isolado para o paciente, pois requer um preparo prévio, no âmbito familiar, social ou profissional, contribuindo para o surgimento de estresse e ansiedade. É aceitável que o paciente cirúrgico apresente tais sintomas, pois a insegurança emerge em situações desconhecidas e é próprio do ser humano ter dúvidas frente a essas situações ${ }^{(1)}$. A origem do estresse e da ansiedade está relacionada ao medo do desconhecido. Portanto, o fornecimento de informações tende a eliminar esse fator estressante.

É atribuição do enfermeiro informar o paciente cirúrgico sobre seu problema de saúde, sobre o procedimento cirúrgico e principalmente sobre como ele poderá participar de sua recuperação pós-operatória, utilizando como ferramenta a orientação pré-operatória, transmitida ao paciente em linguagem clara, respeitando seus conhecimentos e sua cultura.

É inerente ao papel do enfermeiro a atividade educativa, pois ele permanece diuturnamente com o paciente, tendo a oportunidade de conhecê-lo e interagir de maneira mais próxima a seu universo. Essa situação torna esse profissional o elemento da equipe de saúde com maior oportunidade para orientar o paciente.

Vários estudos afirmam que a orientação ao paciente cirúrgico contribui para sua recuperação, diminuindo o medo e a ansiedade e prevenindo complicações. No entanto, é importante identificar o impacto dessas orientações na qualidade de vida e na recuperação do paciente.

Este estudo identificou as mudanças ocorridas no

1 Acadêmico de Enfermagem da Universidade do Sul de Santa Catarina (Unisul).

2 Enfermeira. Mestre em Enfermagem. Professora da Universidade do Sul de Santa Catarina (Unisul). Enfermeira da Clínica Ginecológica do Hospital Universitário da Universidade Federal de Santa Catarina (UFSC).

3 Enfermeira. Mestre em Filosofia, Saúde e Sociedade. Professora da Universidade do Sul de Santa Catarina (Unisul). Enfermeira-chefe da Divisão de Enfermagem em Atendimento Interno do Hospital Universitário da Universidade Federal de Santa Catarina (UFSC). Email: silvanabenedet@gmail.com. 
paciente cirúrgico a partir da orientação pré-operatória e também as relacionou com a forma como essa orientação é realizada pelos enfermeiros. Nesse sentido, estabeleceu como objetivos caracterizar as orientações pré-operatórias realizadas pelos enfermeiros e identificar o impacto da orientação pré-operatória no paciente cirúrgico.

\section{METODOLOGIA}

Este estudo foi realizado em uma unidade cirúrgica de um hospital de ensino de Santa Catarina. Optou-se por um trabalho de campo de natureza exploratório-descritiva, com abordagem qualitativa. Os sujeitos participantes deste estudo foram seis enfermeiros e 25 pacientes cirúrgicos. Em relação aos enfermeiros, cinco eram do sexo feminino e um do sexo masculino. Quanto aos pacientes, dez eram do sexo masculino e 15 do sexo feminino. $\mathrm{Na}$ apresentação dos depoimentos, os enfermeiros foram identificados pela letra "E" e os pacientes, pela letra "P", ambos seguidos do número que Ihes foi atribuído na sequência da entrevista, tudo isso para resguardar a identidade dos participantes do estudo.

Como estratégias metodológicas para a coleta de dados, foram utilizadas a entrevista semiestruturada e a observação sistematizada. A entrevista semiestruturada foi aplicada junto aos enfermeiros em seu local de trabalho, em horário e data escolhidos pelos mesmos e junto aos pacientes no período pós-operatório, conforme suas condições físicas e neurológicas. A observação sistematizada foi realizada nos momentos distintos do processo perioperatório (pósoperatório imediato, primeiro e segundo pós-operatório), quando foi possível perceber de que forma os pacientes reagiam a esse momento no que se referia a dor, mobilização, realização de exercício respiratório e estado emocional.

Esta pesquisa obedeceu aos critérios estabelecidos pela resolução 196/96 do CNS e está registrada no Conep sob número 05.099.4.04.III.

\section{CARACTERÍSTICAS DAS ORIENTAÇÕES PRÉ-OPERATÓRIAS REALIZADAS PELOS ENFERMEIROS}

Quando indagados sobre a orientação no período préoperatório aos pacientes, a maioria dos enfermeiros respondeu afirmativamente, e somente um respondeu não realizar nenhum tipo de orientação.

"Sempre oriento alguma coisa, não dá para cuidar do paciente cirúrgico sem orientá-lo." (E3)

"Nem que seja na hora da visita, mas sempre oriento." (E1)

É de fundamental importância que o enfermeiro adote como atribuição diária a orientação aos pacientes sob sua responsabilidade, principalmente tratando-se de pacientes que serão submetidos à cirurgia, o que, por si só, gera muitas dúvidas, contribuindo para aumentar seu nível de ansiedade.

Os enfermeiros podem ajudar os pacientes e suas famílias a aprenderem como manter a saúde, como restaurá-la ou como se adaptar com maior independência possível ${ }^{(5)}$. Quando o enfermeiro percebe os resultados de sua orientação, ou seja, quando verifica que o paciente adquire conhecimentos e habilidades para lidar com sua necessidades de saúde, é tomado pelo sentimento de satisfação e reconhecimento profissional.

Os enfermeiros entrevistados neste estudo afirmam que a realização da orientação pré-operatória facilitou a recuperação do paciente, diminuindo a ansiedade, reforçando o vínculo entre o paciente e o profissional e, ainda, aumentando a segurança no procedimento.

Sobre o momento em que realizam a orientação pré-operatória, os dados mostram que não existe uma ocasião específica, sendo essa feita em alguns momentos oportunos, como a visita diária, a coleta do histórico de enfermagem e quando solicitado pelo paciente.

As orientações pré-operatórias podem ser fornecidas em um momento não padronizado, desde que as individualidades sejam respeitadas. Dessa forma, cada paciente recebe as informações de forma específica, respeitando seu conhecimento ${ }^{(2)}$. Também é importante que as orientações respeitem a cultura do paciente, com palavras que se aproximem de seu contexto sociocultural.

No entanto, a garantia de um momento formal e específico para a realização de orientações confere maior visibilidade à educação em saúde, fazendo com que os profissionais reconheçam essa atividade como imprescindível a suas atribuições diárias.

É importante também que o enfermeiro envolva os familiares na orientação aos pacientes, pois, mais do que ninguém, a família conhece seu ente. Ela então pode desempenhar importante papel em sua recuperação, não desempenhando os cuidados de enfermagem, mas sim avaliando seu ente e repassando as informações para o enfermeiro, que, à luz da ciência, implementará os cuidados necessários ${ }^{(6)}$.

Quanto aos métodos e recursos que utilizavam para realizar a orientação pré-operatória, a exposição oral, através de uma conversa informal, foi o mais citado.

A conversa informal é sem dúvida uma estratégia valiosa e muito importante na realização da orientação aos pacientes cirúrgicos. Ela possibilita que o paciente se sinta mais à vontade para fazer perguntas e contar suas experiências.

No entanto, a adoção de recursos didáticos pedagógicos mais criativos, não necessariamente dispendiosos financeiramente, facilita $o$ processo de ensino- 
aprendizagem, tornando as orientações mais efetivas.

Uma alternativa proposta é a orientação realizada em grupo. O processo educativo desenvolvido em grupo incentiva a aproximação das pessoas, propiciando o fortalecimento das potencialidades do indivíduo e do grupo, a valorização da saúde, a utilização de recursos disponíveis e o exercício da cidadania a partir do compartilhamento das experiências vividas ${ }^{(6)}$.

O estudo apontou também os motivos que dificultavam a realização das orientações pré-operatórias segundo os enfermeiros entrevistados: falta de programação ou sua não-adoção como atividade prioritária por parte dos enfermeiros, sobrecarga de tarefas, falta de tempo e de disposição dos enfermeiros em realizar as orientações pré-operatórias.

Dada a sobrecarga de trabalho no cotidiano, o enfermeiro desempenha diferentes tarefas, deixando de cumprir seu papel de educador. Isso acontece porque sua atuação está determinada somente pelos objetivos institucionais, não sendo um sujeito e sim um objeto no contexto da instituição( ${ }^{(4)}$. Portanto, cabe a ele mostrar para a instituição que a educação do paciente cirúrgico é algo essencial, e que, no leque de suas atribuições, deve ser considerada e incorporada como uma eficiente ferramenta de trabalho, pois faz com que o paciente se recupere de maneira rápida e com o mínimo de complicações.

\section{IMPACTO DA ORIENTAÇÃO PRÉ-OPERATÓRIA NO PACIENTE CIRÚRGICO}

A enfermagem tem papel fundamental e de grande responsabilidade na recuperação do paciente cirúrgico. As ações de cuidados de enfermagem têm início no período pré-operatório, com orientações sobre o que se constituirá o ato cirúrgico e como o paciente poderá colaborar em sua recuperação, seguindo com cuidados específicos durante o período transoperatório e se estendendo no período pós-operatório até a alta hospitalar.

O processo saúde-doença e o ato cirúrgico podem trazer alterações temporárias e/ou permanentes para o paciente, envolvendo família, trabalho, renda e imagem corporal. Nesse sentido, é necessário inserir o paciente em seu cuidado por meio da orientação pré-operatória, sempre respeitando sua cultura ${ }^{(7)}$.

A identificação das reações dos pacientes deste estudo, após terem recebido orientação pré-operatória realizada pelo enfermeiro, foi possível mediante a observação sistematizada no pós-operatório imediato e também por meio de entrevista nos primeiro e segundo pósoperatórios.

A dor foi relatada por grande parte dos pacientes participantes do estudo.

"Estou sentindo muita dor. Parece uma facada. Já me medicaram, mas não adiantou." (P7)

"A dor vai e volta. Fica sempre latejando. Não quero pedir mais remédio. Então fico quietinha... mas aí doem as costas." (P10)

Uma das principais ferramentas que o enfermeiro possui para o combate à dor é a orientação pré-operatória, pois, quando sabemos que vamos passar por algum acontecimento, logo nos preparamos para tal, com a finalidade de diminuir a agressão, se for o caso. Algo similar ocorre com o paciente quando esse recebe orientações no período pré-operatório: ele se prepara para o procedimento. Ele sabe o que vai ocorrer, e no pós-operatório certamente saberá quando deve pedir ajuda e terá segurança para isso, pois terá consciência de que é seu direito não sofrer, principalmente em se tratando da dor ${ }^{(8)}$.

O estudo apontou que os pacientes que foram orientados realizaram exercícios respiratórios no período pós-operatório, sendo que esse cuidado é prioritário para a prevenção de complicações. O paciente, nesse momento, pode ter retenção de secreções, inibição do reflexo de tosse ou tornar-se relutante a tossir devido à dor. O enfermeiro deve estimular o paciente a realizar exercícios, conforme proposto durante a orientação préoperatória(8).

Sobre a mobilização precoce, os resultados mostraram que os pacientes realizaram alguma forma de mobilização, dentro ou fora do leito. Dessa forma, tomou-se uma das principais medidas para prevenir disfunções circulatórias, como, por exemplo, a Trombose Venosa Profunda (TVP) e, consequentemente, a embolia pulmonar, já que o trombo responsável por causar uma embolia pode facilmente ser formado junto a um processo de TVP(9).

"Não acreditava, mas depois de andar até a dor passou." (P14)

"Achei que ia ficar na cama por dois ou três dias. Operei ontem e já disseram para caminhar, e estou muito bem." (P7)

"Tu vês, só agora eu entendi por que a gente tem que mexer as pernas depois de operado. Achava que não podia nem mexer o pescoço." (P9)

Quanto ao estado emocional, os resultados apontaram que, algumas vezes, foi possível observar mais de uma manifestação no mesmo paciente. A tranquilidade, o bemestar e o otimismo foram apresentados por um número maior de pacientes durante o pós-operatório. Em menor número, os pacientes se demonstraram ansiosos e com medo.

"...gostei muito da conversa que tivemos ontem sobre a cirurgia, fiquei bem tranquila, quando vi já tinha terminado." (P5)

A experiência doença-cirurgia-prognóstico pode gerar 
estresse e outros sentimentos ao paciente, muitas vezes devido ao medo do desconhecido, como o tipo de cirurgia, de anestesia ou até quanto tempo levará para se recuperar ${ }^{(7)}$. É notório o impacto de uma intervenção cirúrgica sobre o paciente, que, na tentativa de extravasar seus sentimentos, pode desenvolver quadros de angústia, depressão e isolamento ${ }^{(9)}$.

O sentimento de ansiedade é a principal causa de dúvidas e incertezas que caminham com o paciente cirúrgico, mas isso pode ser amenizado com instruções e orientações da equipe de enfermagem ${ }^{(2)}$.

O fato de a maioria dos pacientes deste estudo apresentar tranquilidade, bem-estar e otimismo comprova que, quando os pacientes cirúrgicos estão cientes dos acontecimentos perioperatórios, passam pela experiência cirúrgica com um índice de estresse, ansiedade e medo diminuído.

Como mostra este estudo, o grau de orientação do paciente cirúrgico está intrinsecamente ligado a sua recuperação, pois, quando o paciente não tem clareza do que acontecerá durante o processo cirúrgico, tende a ficar mais ansioso, desencadeando uma série de reações fisiológicas que podem dificultar sua recuperação.

As medidas educacionais precisam ser contínuas e os indivíduos devem ser tratados como únicos, com sua história, problemas e dúvidas, para que os objetivos da orientação sejam atingidos ${ }^{(3)}$.

O processo de orientação dentro da clínica cirúrgica deve ser contínuo, possibilitando ao paciente uma eficaz recuperação cirúrgica, com o mínimo de complicações possíveis. Caso isso não seja possível, que esse paciente compreenda seu quadro, diminuindo a ansiedade $\mathrm{e}$ possibilitando que participe de sua recuperação.

\section{CONSIDERAÇÕES FINAIS}

Os resultados deste estudo evidenciaram o papel do enfermeiro como principal elemento na educação dos pacientes cirúrgicos e a importância de adotar como atribuição diária a orientação aos pacientes sob sua responsabilidade. Tais orientações mostraram-se efetivas, podendo ser realizadas em momentos não padronizados, como na realização do histórico, durante a passagem da visita diária, utilizando a conversa informal. Dessa maneira, valorizam-se as dúvidas e necessidades apresentadas pelos pacientes.

A orientação pré-operatória fez com que os pacientes cirúrgicos manifestassem, no pós-operatório, sentimentos de tranquilidade, bem-estar, otimismo e diminuição do medo e da ansiedade. Além disso, realizaram mobilização precoce e exercícios respiratórios, fatores que, consequentemente, contribuíram para uma recuperação mais rápida e com um índice menor de complicações.

Portanto, este estudo mostrou que a realização da orientação préoperatória de maneira individualizada influenciou na melhoria da qualidade de vida do paciente cirúrgico, diminuindo o medo e a ansiedade e prevenindo complicações no pós-operatório, aumentando a confiança do paciente no enfermeiro e conferindo maior satisfação profissional.

\section{Referências}

1. Galdeano LE, Rossi LA. Construção e validação de instrumentos de coleta de dados para o período perioperatório de cirurgia cardíaca. Rev Latinoam Enferm. 2006;10(6):800-04.

2. Benedet SA. Cliente cirúrgico: ampliando sua compreensão [dissertação].

Florianópolis: Universidade Federal de Santa Catarina; 2002.

3. Farias FLR. Educação e saúde no trabalho da enfermagem com dependentes químicos. Texto Contexto Enferm. 2005;12(1):52-8.

4. Villa EA, Cadete MVM. A cultura institucional como determinante da prática educacional do enfermeiro. Texto Contexto Enferm. 2000;9(3):115-32.

5. Pinto TV, Araujo IEM, Gallani MCBJ. Enfermagem em cirurgia ambulatorial de um hospital-escola: clientela, procedimentos e necessidades biológicas e psicossociais. Rev Latinoam Enferm. 2005;13(2):208-15.

6. Silva DG. Grupos como possibilidades para desenvolver educaçăo em saúde. Texto Contexto Enferm. 2003;12(1):97-103.

7. Carvalho, ARS, Matsuda, LM, Stuch, RAG, Coimbra, JAH. Investigando as orientaçōes oferecidas ao paciente em pós-operatório de revascularização miocárdica. Rev Eletrônica Enferm. 2008;10(2):504-12.

8. May L. A atuação da enfermeira frente à dor do cliente em pós-operatório uma abordagem humanizada [dissertação]. Florianópolis: Universidade Federal de Santa Catarina; 2002.

9. Smeltzer S, Bare B. Brunner e Sudarth: tratado de enfermagem médicocirúrgica. Rio de Janeiro: Guanabara Koogan; 2008. 